\title{
Wave Induced Motions of Irregular Shaped Ice Mass close to Fixed Structure
}

\author{
Tanvir Sayeed, Faisal Althobiani
}

\begin{abstract}
Small ice pieces can pose significant threat to offshore platforms located in ice covered waters. Impact load due to iceberg and small ice fragments is important design consideration of such structures. The impact velocity and near vicinity hydrodynamic interaction significantly effects the impact load. In recent studies, Sayeed et al. [19, 20] investigated the hydrodynamic interaction of simple shaped ice masses heading towards a fixed platform in regular waves. It was found that the motions of the approaching ice mass is influenced by the standing wave and the distance to wave length ratio dictates the ice mass motion due to wave impact. In this paper, previous experimental data collected by Sayeed et al. [18] is reanalyzed to examine the wave kinematics of an irregular shaped ice mass heading to a fixed structure. Surge and heave velocities plotted against separation distance / wavelength show similar trends as observed by Sayeed et al. [20]. The stationary wave profile is found to be most influential factor on kinematics of the approaching ice mass.
\end{abstract}

Keywords : Iceberg, Wave Body Interaction, Wave Hydrodynamics, Fixed Platform

\section{INTRODUCTION}

Different sized ice fragments can become significant threat to fixed or floating offshore platforms in ice infested regions. The structural design of fixed structures has to consider global and local iceberg impacts. Wave driven slight ice fragments are difficult to notice in harsh climate conditions. Moreover, the short impact duration and higher velocity of impact can intensify the impact load for smaller pieces [10]. The velocity of wave driven ice masses just prior to impact with an offshore platform largely effects the associated impact force. The near vicinity hydrodynamics play a significant role in governing the final velocity of impact. For slender platforms like semi-submersibles, the hydrodynamic proximity effect is less and the open water velocity of ice mass can be a reasonable estimate for impact velocity ([10], [12]). For Gravity Base Structures (FPSOs), the hydrodynamic effects can be substantial due to modified wave field around the structure and impact velocities should be estimated considering those effects ([12], [13]).

Various experiments demonstrated that the close proximity hydrodynamics influences the trajectory of the approaching body and impact velocity. It was reported that

Revised Manuscript Received on December 05, 2019.

* Correspondence Author

Faisal Althobiani *, Faculty of Maritimes Studies, King Abdulaziz University, Jeddah 21589 Email: dr.althobiani@ gmail.com

Tanvir Sayeed, Ph. D., P. Eng. Research Council Officer at National Research Council Canada. the ice mass will drift the structure and will not hit if diameter of the model is less than half of the platform diameter ([6], [7], and [17]). In the cases of impacts, the velocity can be significantly reduced and other hydrodynamic phenomenon due to complicated wave field around the platform can affect the impact process and the corresponding impact loads ([2], [3], [4], and [5]). Attwood [1], and Lever et al. $[10,11]$ conducted multiple experiments and found that smaller icebergs (ratio of wave length to iceberg size > 13) behave similar to fluid particles. Lever et al. [11] included random iceberg shape as an additional factor in the probability distribution of impact velocity which showed significant higher variations in surge velocity. Mak et al. [13] conducted similar studies with a floating platform and revealed that open water significant velocities of bergy bits can be $10-40 \%$ overestimation when considered as significant impact velocities.

The proximity effects on a drifting iceberg approaching a fixed structure were conducted by McTaggart [16], and Isaacson and McTaggart ([7], [8]) through experiments and numerical analysis. The authors reported no impact in waves when the value below 0.2 (diameter ratio iceberg to structure). Salvalaggio and Rojansky [17] reported this ratio to be 0.5 in their model experiments. Due to the presence of the platform, it was also reported that the velocity of smaller ice masses (the diameter ratio of iceberg and structure below 0.2 ) gets $10 \%$ or more reduced prior to impact. Colbourne et al. [3] conducted model experiments with an FPSO and approaching iceberg and bergy bit. The radiated waves and near field actions resulted in confusing impact actions where in some cases the model was accelerated towards the vessels and in other cases the model drifted and passed by the side of the vessel. Colbourne [4] also reported that increased wave may result in reduced impact due to the reflected waves and the reflected and radiated waves generate a complicated wave field in the near vicinity of the vessel.

Gagnon [6] reveled the effect of negative drift force when a tanker passed by a floating ice model during his experiments. The motion of the tanker and standing wave resulted in increased sway motion of the ice model which eventually cause reduced collision velocity.

McGovern and Bai [14] found that ice floe subjected to waves exhibits different motions than icebergs and behaves similar to fluid particles the ratio of wavelength and characteristic floe length is in the range of 3.3 to 5 . McGovern and Bai [15] also reported how a stationary fixed cylinder affects the wave induced motions of ice models in waves. 


\section{Wave Induced Motions of Irregular Shaped Ice Mass close to Fixed Structure}

Significant reductions in increased heave motions and surge were reported at locations where the ratio of separation distance to cylinder diameter is less than 10. The drift velocities were also negative and low when the ice iceberg was very close to the fixed cylinder.

Sayeed et al. [19] examined the wave forces on spherical ice masses of different diameters at a fixed platform by different separation distances. The ratio of separation distance to wavelength governed the wave forces in heave directions and surge. Surge mean drift force for most cases was also negative when the model was very close to the platform. It was also found that surge RMS forces decreased and heave RMS forces increased when the model was very near to the structure. Sayeed et al. [20] conducted free floating experiments with the same models and same fixed platform. The wave induced motion data showed similar trends as obtained in [19]. The ratio of separation distance / wavelength was found to be the most influential factor. The motions were amplified at nodal and anti-nodal locations of the standing wave envelope. When the model approached near to the platform, the surge induced motion reduced but heave motion was increased at the same time.

In the present study, previous experimental data collected by Sayeed et al. [18] for an irregular shape ice mass is reanalyzed to identify possible correlation of wavelength with the spatial motion history in front of the fixed structure. Heave velocities and surge of the ice model are plotted against separation distance / wavelength and the influence of non-propagating standing wave in front of the platform on kinematics of the ice mass is discussed.

\section{MATERIALS AND METHODS}

Free floating experiments were conducted investigate the kinematics of an irregular shaped ice mass as it approaches to a fixed platform. The experimental campaign is discussed in details in this section.

\section{A. Facility}

The facility used for the experiments was the towing tank of Ocean Engineering Research Center at Memorial University of Newfoundland, Canada. The tank is $58 \mathrm{~m}$ long and $4.5 \mathrm{~m}$ wide with a wave board (hydraulically) on one end and a sandy beach to absorb waves on the other side. The maximum still water depth is $2.2 \mathrm{~m}$ and maximum generated wave height is $0.2 \mathrm{~m}$.

\section{B. Instrumentation and Models}

An aluminum cylinder in hexagonal shape of $1.22 \mathrm{~m}$ diameter and $2.3 \mathrm{~m}$ height was used as a offshore static platform. The structure was ballasted with full water and the tow carriage was placed behind the structure to add support to keep it stationary during wave actions. The basin width was 3.6 times the platform diameter which ensured no blockage effect and minimum wave reflections from tank walls. The ice mass was fabricated by bonding and stacking multiple irregular sized blocks polypropylene. Two small weight thin rods were used to guide the iceberg close to the platform. To track motions four passive marker balls on top of four sticks were installed on the model. Fig. 1 shows the fixed platform on the left and the irregular shaped ice mass on the right.
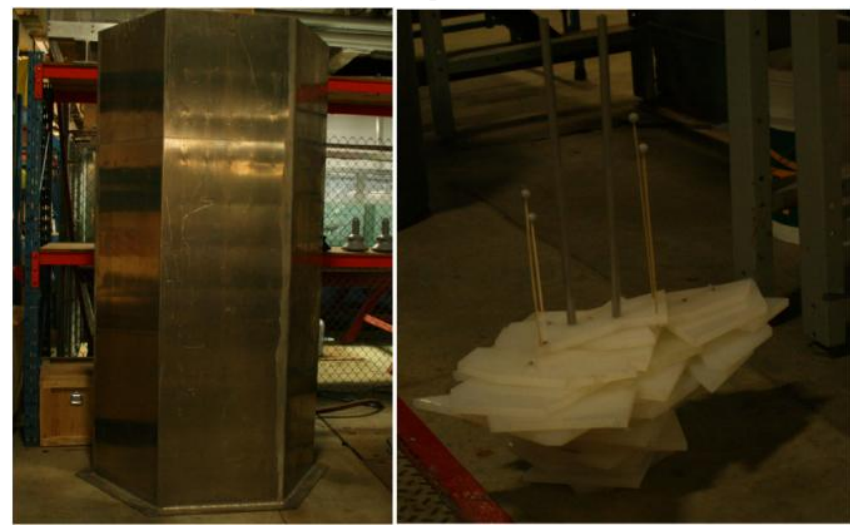

Fig. 1: Fixed structure and Irregular shape ice mass

Six degree of freedom model motions were measured using optical tracking system called Qualisys(C). The system utilized three infrared cameras to cover the region of interest. The incoming and reflected wave profiles were measured using capacitance type wave probes. The tracking system and the wave probes were calibrated prior to conducting experiments. Digital still pictures were taken during experiments and videos were recorded.

\section{Environment Condition}

The still water depth was $1.83 \mathrm{~m}$ during the experiments and the wave heading was 180 degrees. Five regular waves with different wavelengths and same wave height and were chosen as multiples of platform diameter. Table 1. shows the wave particulars used in the experiments.

Table 1: Wave particulars [18]

\begin{tabular}{|c|c|c|c|}
\hline $\begin{array}{c}\text { Wave } \\
\text { (Name) }\end{array}$ & $\begin{array}{c}\text { Wave Height } \\
(\mathbf{c m})\end{array}$ & $\begin{array}{c}\text { Wavelength } \\
(\text { *D) }\end{array}$ & $\begin{array}{c}\text { Wave Period } \\
(\mathbf{s})\end{array}$ \\
\hline Wave_1 & 8 & 1 & 0.884 \\
\hline Wave_2 & 8 & 1.5 & 1.08 \\
\hline Wave_3 & 8 & 2 & 1.251 \\
\hline Wave_4 & 8 & 2.5 & 1.39 \\
\hline Wave_5 & 8 & 3 & 1.53 \\
\hline
\end{tabular}

\section{Methodology}

In order to guide the model heading towards the platform and reach close to it, a guiding mechanism as shown in Fig. 2 was used. Without such guiding, the model may deviate from the desired course and may drift away from the structure. Such guiding mechanism forces the model close to the platform so that the hydrodynamic interactions between the model and the platform can be investigated in near proximity.

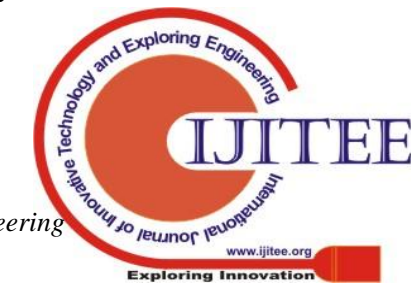




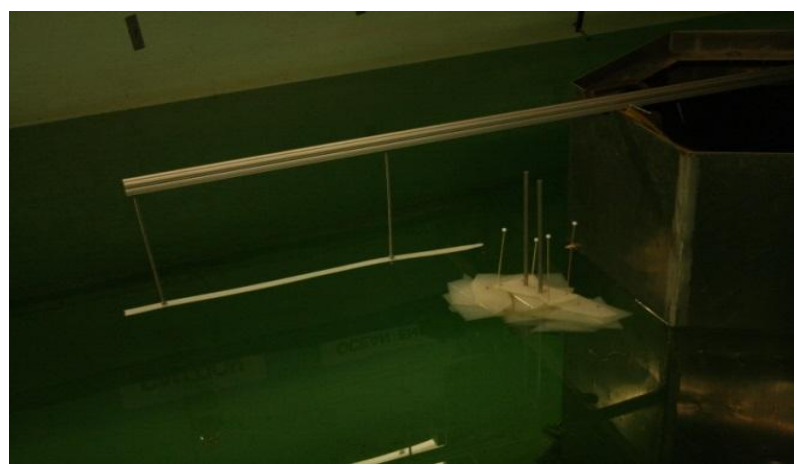

Fig. 2: Irregular iceberg with guiding mechanism [18]

During these tests, the ice model was positioned at a distance $(\sim 1.3 \mathrm{~m})$ in front of the face of the platform. The model was held in position and let some wave cycles to pass by before releasing under wave actions. Fig. 3 shows the ice model subjected to waves with the fixed platform during a wave test.

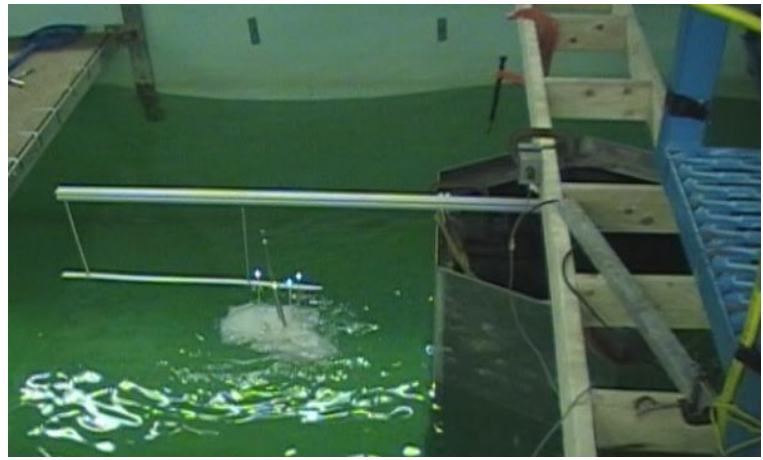

Fig. 3: Irregular ice mass during wave test

\section{RESULTS \& DISCUSSION}

The data was collected with a sampling frequency of 65 $\mathrm{Hz}$ during the tests. The available data are the time series 6 degrees of freedom (DOF) motion for the irregular ice mass subjected to five regular waves in the presence of the structure. For the purpose of the present study, surge and heave data analyzed and presented in this section.

Figure 4 shows the drift motion time series for all the tested waves. The ice model did not hit the platform for waves 4 and 5. For wave 5, the model remained further away from the structure than wave 4 . For the rest of the waves, the ice model had either single or multiple impacts with the platform before moving around and passing the platform.

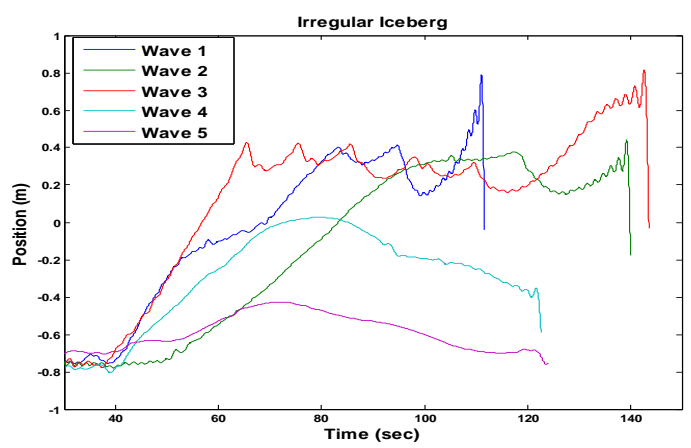

Fig. 4: Irregular ice mass position time history in waves [18]
Sayeed et al. [19, 20] identified strong influence of standing wave on the kinematics of ice masses in front of fixed platform. When the incoming wave is obstructed by a vertical wall, the waves get reflected from the wall. The superposition of incoming and reflected waves generate standing wave profile which does not propagated in either directions. Fig. 5 shows the theoretical standing wave profile with associated nodes and antinodes that will be generated in front of vertical wall. For the tested platform, not all the waves are reflected, rather partial standing waves were generated in front of the face of the platform

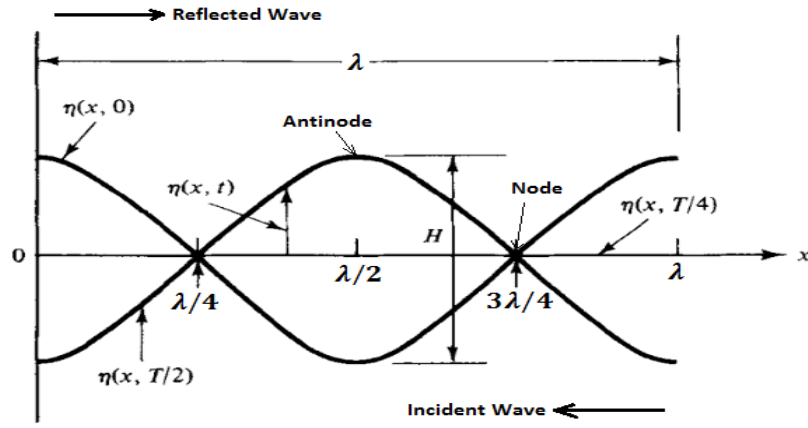

Fig. 5: Wave profile (standing) in front of vertical structure [5]

In order to find the effect of the standing wave on the wave induced motions of the ice mass in front of the structure, heave motions and surge are considered and both displacements were differentiated to estimate the associated heave velocity and surge and plotted separation distance / wavelength.

Figs. 6 to 10 shows the heave velocities and surge for the ice mass heading towards the fixed platform in all waves and plotted against separation distance / wavelength. The separation distance from the platform was obtained from the drift components with low frequency of surge motion data. It is to be noted that the spikes in figs. 6 are due to the dropouts in Qualisys@ data and not real.
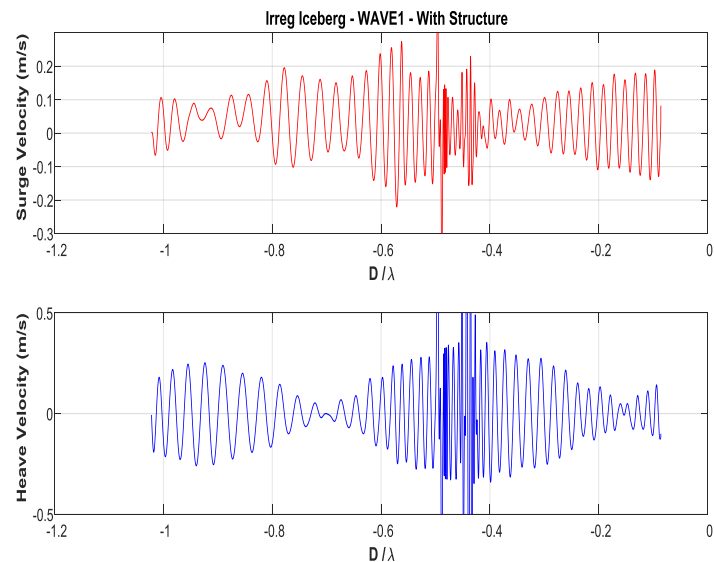

Fig. 6: Heave velocity and Surge of ice model in wave_1 


\section{Wave Induced Motions of Irregular Shaped Ice Mass close to Fixed Structure}
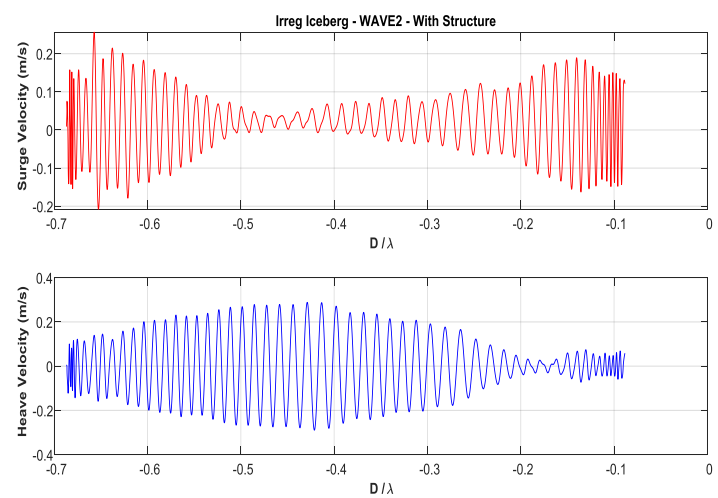

Fig. 7: Heave velocity and Surge of ice model in wave_2
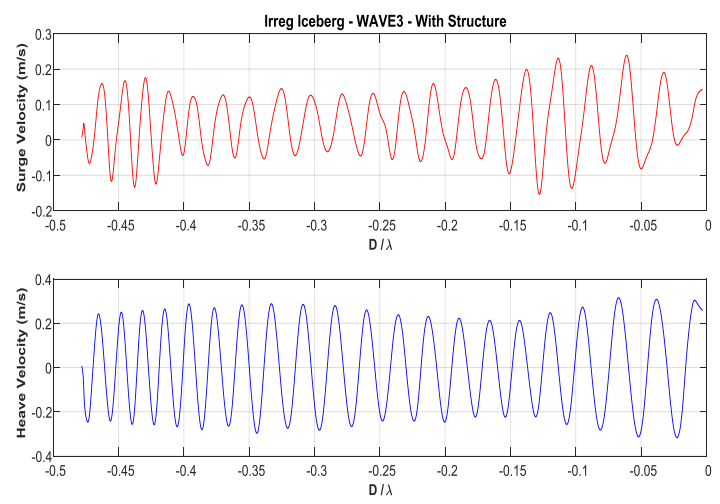

Fig. 8: Heave velocity and Surge of ice model in wave_3

These results clearly demonstrate the influence of standing wave envelope on the motions of the ice model in front of the platform. The heave motions and surge are amplified at nodal and anti-nodal locations of the standing wave profile. Also as the ice mass approaches very close to the platform, the motion slows down in surge direction and the motions in heave direction increase. All these results are consistent with the recent findings by Sayeed et al. [19, 20] and the ratio of separation distance / wavelength is found to govern the corresponding kinematics of the ice mass.
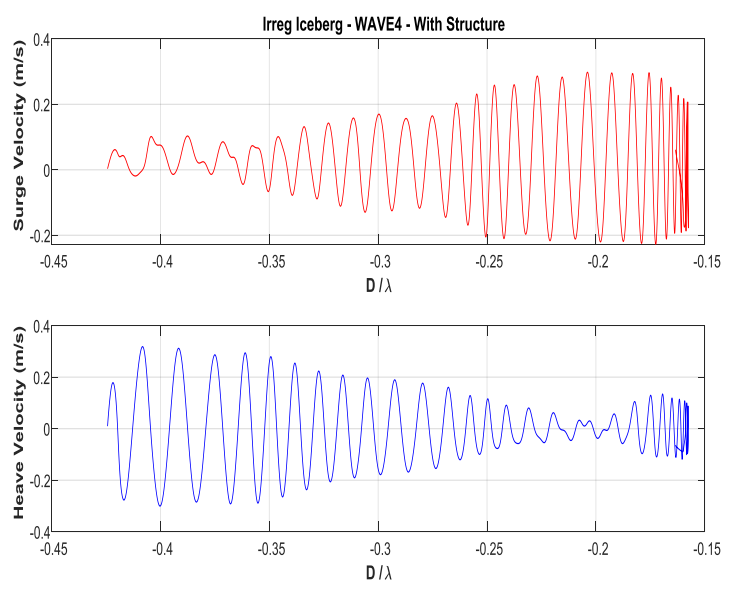

Fig. 9: Heave velocity and Surge of ice model in wave_4
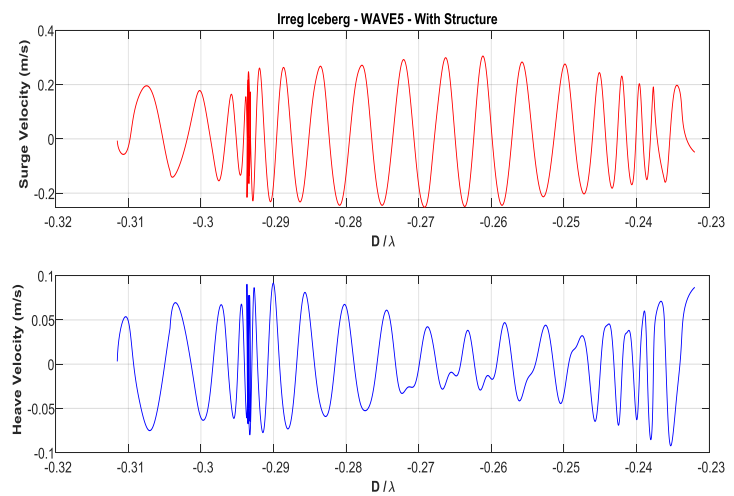

Fig. 10: Heave velocity and Surge of ice model in wave_5

\section{CONCLUSION}

Offshore platforms in ice covered waters have to withstand the impact loads from iceberg and smaller ice fragments. The hydrodynamic interaction between the offshore platform and iceberg the in near proximity is an influential factor which effects this impact load. Experimental data [18] on the free floating motions of an irregular ice mass approaching a fixed structure is reanalyzed following the same procedure as [20] which reveals consistent results with all the recent studies. It is evident that the motions of the irregular shape ice mass also follows the same patterns like the spherical and cylindrical models. The stationary wave developed by the combination of incoming and reflected components of waves, influences the motions of the approaching body. Surge and heave motions are changed accordingly based on the nodal or anti-nodal locations in the standing wave profile. If the ice mass approaches to the fixed platform, the surge motions decrease and the heave motions increase. Such reductions in wave induced surge motions and drift can result in reduced impact forces in surge direction. Simultaneously, the increased heave motions in near vicinity may result in potential hits with topsides and other hanging structures which are not designed as ice resistant.

\section{REFERENCES}

1. Attwood, D. (1987). "Wave Induced Motion of Small Ice Masses", Masters' thesis, Memorial University of Newfoundland

2. Bolen, Z. K. (1987). "Estimation of Loads Due to Simultaneous Occurrence of Waves and Iceberg Impacts",OTC-5599, Offshore Technology Conference, Houston, Texas.

3. Colbourne, D. B., Simoes Re, A., Drodge, R., \& Sullivan, M. (1998) “Terra Nova FPSO Iceberg Impact Tests". IMD Report TR-1998-18 (Protected) to SOFEC Inc.

4. Colbourne, D.B. (2000). "Scaling Pack Ice and Iceberg Loads on Moored Ship Shapes", Oceanic Engineering International, Vol. 4, No.1, pp. 39-45.

5. Dean, R. G., Dalrymple, R. A. (1991). "Water Wave Mechanics for Engineers and Scientists”, World Scientific, 1991.

6. Gagnon, R. E. (2004). "Physical Model Experiments to Assess the Hydrodynamic Interaction between Floating Glacial Ice Masses and a Transiting Tanker". Journal of Offshore Mechanics and Arctic Engineering, Vol. 126, No. 4, pp. 297-309.

7. Isaacson, $\mathrm{M}$. and McTaggart, $\mathrm{K}$. (1990a). "Iceberg Drift Motions 
Near a Large Structure", Proceedings of the First Pacific/Asia Offshore Mechanics Symposium, Seoul, Korea.

8. Isaacson, M. and McTaggart, K. (1990b). "Modelling of Iceberg Drift Motions Near a Large Offshore Structure", Cold Regions Science and Technology, Vol. 19, pp. 47-58.

9. Lever, J.H., Attwood, D. and Sen, D. (1988a). "Factors Affecting the Prediction of Wave-Induced Iceberg Motion". Cold Regions Science and Technology, Vol. 15, pp. 177-190.

10. Lever, J.H., Colbourne, B. and Mak, L. (1988b). "A Model Study of the Wave-Induced Motion of Small Icebergs and Bergy Bits". Journal of Offshore Mechanics and Arctic Engineering, Vol. 110, No. 1, pp. 101-107.

11. Lever, J.H., Sen, D., Attwood, D., (1990a). "The Influence of Shape on Iceberg Wave-Induced Velocity Statistics". Journal of Offshore Mechanics and Arctic Engineering, Vol. 112, No. 3, pp. 263-269.

12. Lever, J.H., Colbourne, B. and Mak, L. (1990b). "Model Study of Wave-Driven Impact of Bergy Bits with a Semi-Submersible Platform". Journal of Offshore Mechanics and Arctic Engineering, Vol. 112, No. 4, pp. 313-322.

13. Mak, L. M., Lever, J. H., Hinchey, M. J., and Duthinh, D. (1990). "Wave-Induced Bergy Bit Motion Near a Floating Oil Production Platform", Proceedings of the 9th International Conference on Offshore Mechanics and Arctic Engineering, Vol. IV, pp. 205-215.

14. McGovern, D.J., and Bai, W. (2014a). "Experimental Study on Kinematics of Sea Ice Floes in Regular Waves”, Cold Regions Science and Technology, Vol. 103, pp. 15-30.

15. McGovern, D.J., and Bai, W. (2014b). "Experimental Study of Wave-Driven Impact of Sea Ice Floes on a Circular Cylinder", Cold Regions Science and Technology, Vol. 108, pp. 36-48.

16. McTaggart, K. A. (1989). "Hydrodynamics and Risk Analysis of Iceberg Impacts with Offshore Structures", Ph.D. thesis, University of British Columbia.

17. Salvalaggio, M. A. and Rojansky, M. (1986). "The Importance of Wave-Driven Icebergs Impacting an Offshore Structure", OTC-5086, Offshore Technology Conference, Houston, Texas.

18. Sayeed, T., Colbourne, B., Peng, H., Colbourne, B., and Spencer, D. (2015). "Experimental Investigation of Ice Mass Hydrodynamic Interaction with Offshore Structure in Close Proximity". Proceedings of the 34th International Conference on Ocean, Offshore and Arctic Engineering, OMAE 2015, St. John's, NL.

19. Sayeed, T. M., Colbourne, B., Molyneux, D., Akinturk, A. (2017). Experimental and Numerical Investigation of Wave Forces on Partially Submerged Bodies in close Proximity to a Fixed Structure, Ocean Engineering, Vol. 132, pp. 70-91.

20. Sayeed, T. M., Colbourne, B., Molyneux, D., Akinturk, A., Zaman, H. (2018). Experimental and Numerical Investigation of Wave Induced Motions of Partially Submerged Bodies Approaching a Fixed Structure, Ocean Engineering, Vol. 155, pp. 115-130.

\section{AUTHORS PROFILE}

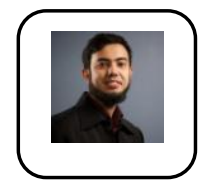

Tanvir Sayeed, Ph. D., P. Eng. Research Council Officer at National Research Council Canada. He has experiences in different research areas such as. Numerical Modelling \& Simulation Physical Model Testing, Hydrodynamic analysis, Naval Architecture, Experimentation and Data Analysis, Project Management \& Documentation Skill Programming ( Matlab, Fortran, $\mathrm{C} / \mathrm{C}++$ ) etc.

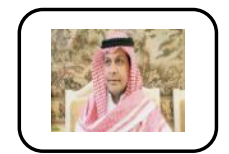

Dr. Faisal AlThobini, Currently is assistant Professor in the Faculty of Maritime Studies - Marine Engineering Department Dr Faisal was research assistance in the Centre for Efficiency and Performance Engineering. He received Environmental Monitoring degree from University of Leeds, and Mechanical Engineering degree from Jeddah Technical College, BSc in Electrical Engineering from Riyadh Technical College before completing a Master's degree in Advanced Control and Systems Engineering at the University of Manchester. He was awarded a $\mathrm{PhD}$ from the University of Huddersfield in the non-intrusive detection of incipient cavitation of centrifugal pump 